\title{
Psychological empowerment of NGO women in Iran: Designing a tool
}

Fataneh Bakhshi ${ }^{1}$, Davoud Shojaeizadeh ${ }^{2}$, Roya Sadeghi ${ }^{3}$, Saharnaz Nedjat ${ }^{4}$, Mohammad Hossein Taghdisi ${ }^{5}$, Glenn Laverack ${ }^{6}$

${ }^{1}$ Ph.D. Candidate of Health Education and Promotion, Department of Health Education and Promotion, School of Public Health, International Campus, Tehran University of Medical Sciences, Tehran, Iran

${ }^{2}$ Ph.D. of Health Education and Promotion, Professor, Department of Health Education and Promotion, School of Public Health, International Campus, Tehran University of Medical Sciences, Tehran, Iran

${ }^{3} \mathrm{Ph}$.D. of Health Education and Promotion, Associate Professor, Department of Health Education and Promotion, school of Public Health, International Campus, Tehran University of Medical Sciences, Tehran, Iran

${ }^{4}$ Ph.D. of Epidemiology and Biostatistics, Professor, Department of Epidemiology and Biostatistics, School of Public Health, Knowledge Utilization Research Center, Tehran University of Medical Sciences, Tehran, Iran

${ }^{5} \mathrm{Ph}$.D. of Health Education and Promotion, Professor, Department of Health Education and Promotion, School of Public Health, Iran University of Medical Sciences, Tehran, Iran

${ }^{6}$ Ph.D. of Health promotion, Honorary Professor, School of Public Health, South Denmark University, Odense, Denmark

\section{Type of article: Original}

\begin{abstract}
Background: As the core of health promotion, proper assessment of empowerment is a base for planning for a process that increases people's control on their decisions, lifestyle, and effective activities for their health.

Objective: To design and develop a special tool to assess the empowerment of NGO women in Iran.

Methods: This successive exploratory study of combinational type was conducted in 2015 in two steps. In the first step, using comments of participants and the help of authentic texts related to this field, dimensions of psychological empowerment were developed. In the second step, psychometric properties of the scale or tool were determined using formal content, and structural validity and reliability were determined using internal consistency and stability via SPSS version 21.

Results: In the first step, the initial tool including 58 items was developed in the form of eight domains. In the second step, based on exploratory factor analysis (EFA), the number of items was reduced to 37. Considering the eigenvalues of higher than one, items were classified into eight factors. KMO index was 0.896 in this study. Reliability of the tool was 0.81 using Cronbach's alpha. This tool is able to predict $66.1 \%$ of total changes in psychological empowerment.

Conclusion: A questionnaire with relevant reliability and validity, including eight domains of participation, motivation, cognitive thinking, critical thinking, self-efficacy, intention, perceived control and social support was developed to measure psychological empowerment of NGO women in Iran.
\end{abstract}

Keywords: Empowerment; Women; NGOs; Psychometric Properties

\section{Introduction}

Currently, as in the rest of the world, one of the effective strategies for comprehensive and sustainable development in Iran, is to employ people's participation and empowerment in all its dimensions. The major tool to achieve this goal is to establish Non-Governmental Organizations (NGOs) that are created based on the need and ability of various groups in assorted and essential fields, to implement development plans (1). Most activities of NGOs in

\section{Corresponding author:}

Professor Dr. Davoud Shojaeizadeh, Department of Health Education and Promotion, School of Public Health, International campus, Tehran University of Medical Sciences, Tehran, Iran.

Tel: +98.2142933000, Fax: +98.2188989128, Email: shojaei@tums.ac.ir

Received: September 03, 2016, Accepted: October 25, 2016, Published: September 2017

iThenticate screening: October 19, 2016, English editing: August 15, 2017, Quality control: August 20, 2017

(C) 2017 The Authors. This is an open access article under the terms of the Creative Commons Attribution-NonCommercialNoDerivs License, which permits use and distribution in any medium, provided the original work is properly cited, the use is non-commercial and no modifications or adaptations are made. 
developing countries are to provide opportunities and facilities including education, skills, social networks and employment. In addition, some of them directly contribute to the empowerment of society (2). In Iran, these activities are focused on empowering the community to facilitate participation, if required (3). The use of local capacities, especially in the health system, also has a long history in Iran (4). One of the volunteer groups that has grown significantly in recent years, and has provided important health and community-based interventions, is the "Health Companions Group". This group is mainly composed of women. Part of the dedicated goals of this NGO, which operates under the auspices of the Welfare Organization, are as follows: efforts to change the ordinary way of people's lives; trying to create a space for people's participation in decision-making to solve their own, their neighborhood and their community's problems; efforts to create a sense of collective responsibility (empathy, interaction, etc.); increasing personal and social skills; providing required grounds for collective decision-making for changes and learning; empowering people in accordance with the conditions of today's life; providing a favorable context for public participation and creating a sense of individual and collective independence (5). In line with the goals of various NGO groups, empowerment could be a powerful driver for their participation and other groups trained by them. Measuring empowerment is an important step in planning to increase and maintain it. In addition to the World Health Organization (WHO), other global organizations such as the World Bank and the United Nations have highlighted the empowerment of women. Women working in NGOs should be so empowered that they can empower their clients and create changes in their behavior. However, despite the efforts of this group, due to lack of empowerment in members, the effectiveness of achieving NGO goals is not yet observed (6). Therefore, empowerment of NGO members has become a priority. In this regard, the Welfare Organization of Iran is also seeking to find a way to empower Health Companions (5). For the optimal empowerment of individuals, an initial assessment of their current ability is essential. There are some tools to measure psychological empowerment (7-12). Scrutinizing these studies, it can be realized that researchers have tried to use the most appropriate tools to measure the empowerment of their research community. Therefore, it appears that to measure psychological empowerment in each community, local tools should be used proportional to the culture of that community (13). Considering that most researchers working on empowerment in Iran, have employed inventories of foreign studies or they have developed their own inventories for their target group and no special tool is yet developed in Iran for NGO members, this study was conducted with the aim of designing and developing a specific tool to measure empowerment of various NGO members in Iran.

\section{Material and Methods}

In this exploratory study, a combination of qualitative and quantitative methods was used to achieve the initial scale or tool and to explore the relations among its dimensions. The following steps were involved:

\subsection{First step: Providing the content of questionnaire}

\subsubsection{Reviewing texts:}

To prepare this questionnaire, first, to determine domains, Google scholar, Medline, Science Direct, PubMed, Proquest, and Magiran databases were searched using keywords of empowerment, individual empowerment, and psychological empowerment. Then, all papers with individual or psychological empowerment questionnaires as well as papers where various dimensions related to individual or psychological empowerment, were selected. After analyzing the selected papers, dimensions mentioned in them were listed to be used as a base of available dimensions in scientific texts.

\subsubsection{Surveying experts:}

After reviewing available studies and becoming familiar with intended dimensions in them, due to the diversity of existing domains in various studies and lack of a specific questionnaire for the group under study, i.e. NGO women, views of these women were investigated via semi-structured interviews in the form of a qualitative content analysis approach. To this purpose, a group of people were selected among the members of this population and entered this stage at their own volition. Interviews continued to complete data saturation. Then, extracted data were classified to define psychological empowerment of volunteer women and its dimensions. After analyzing data obtained from interviews, a focus group was employed to summarize and complete the comments and to determine the main areas of the questionnaire. This process involved in-depth individual interviews with 23 members and holding two focus group sessions. Then, to develop questions for each domain, databases were again searched. Searching was conducted based on the title of each domain and all available questions in that domain were collected. The questions were reviewed and corrected through several stages of assessment and consultation with professors and specialists, and the initial tool consisting of eight domains was produced in the form of 58 items or questions. 


\subsection{Second step: Psychometric of the questionnaire}

In this step, validity and reliability of the initial produced tool was measured via the following measures:

\subsubsection{Measuring Validity}

To determine internal content validity, the questionnaire was given to 17 specialists ( 12 experts of health promotion, a sociologist, a specialist in Health Services Management, a nurse, a nutritionist, and a methodologist) who were content experts with masters and $\mathrm{PhD}$ degrees. In addition, the questionnaire was given to ten lay experts including 8 female NGO members and two employees of the Welfare Organization to review and comment on it. For consistency in answering, a form was provided along with the intended questionnaire, and was given to all abovementioned people to determine the relevance and clarity of all questions and comprehensiveness of the total questionnaire. They were asked to score these questions between 1 and 4 ( $1=$ totally relevant to $4=$ totally irrelevant $)$ according to the definition provided for the cases mentioned in the form and provide their views to improve the questions of this inventory. In addition, to determine content validity ratio (CVR), the necessity of each question was asked. In addition, at the end of this form, one section was provided for extra comments on the questionnaire. Answers were collected during 3 to 4 weeks. To determine the formal validity, respondents were asked to comment on the formal shape and appearance of the questionnaire. To determine structural validity, exploratory factor analysis was conducted after considering required presuppositions.

\subsubsection{Content Validity Index of Items (I-CVI):}

To determine the indices of clarity and relevance of all questions, the sum of questions that specified the clarity and relevance of each question as totally favorable or favorable (scores 3 and 4), were divided to the total number of responding experts.

2.2.1.2. Scale Content Validity Index-Average (S-CVI/Ave):

There are various methods to calculate the general relevance and clarity of the tool (14). In this study, the mean approach was used where the sum of I-CVI was divided into the total number of the questions in the questionnaire. The comprehensiveness of the tool was obtained from dividing the number of experts, who had recognized the comprehensiveness of the tool as favorable, to the number of total experts (15).

\subsubsection{Content Validity Ratio (CVR):}

The content validity was calculated using the quantitative method of counting the votes of experts who chose the option of the necessity of each item.

\subsubsection{Exploratory Factor Analysis (EFA) to determine structural validity:}

Considering that the research tool in this study had been designed for the first time, exploratory factor analysis was used to explain the correlation pattern between questions of each domain. Special attention is paid to factor analysis as one of the most reliable methods for determining the validity of the tool, especially for those tools that measure the psychological characteristics (16). Knapp and Brown (1995) have accepted the required number of samples as a minimum three subjects for each variable (17). To this purpose, 290 samples, i.e. over six samples for each item, were selected randomly. The inclusion criteria were being an NGO member for over 6 months, being literate and willing to participate in the study. An informed consent approved by Tehran University of Medical Sciences was obtained from all participants in all stages of the study.

\subsubsection{Measuring Reliability}

\subsubsection{Calculating Intra-Class Correlation (ICC) and Cronbach's alpha:}

After conducting validity stages, to determine the reliability of the tool, intra-class correlation and stability were used. Since this tool is designed based on a Likert scale that included the total score of questions or items, it should be assessed in terms of intra-class correlation. Cronbach's alpha also represents group relevance of items that measure a structure or a domain. Typically, a Cronbach's alpha between 0.70 and 0.80 is acceptable (18). To this purpose, the questionnaire corrected at validity stage, was given to 36 female NGO members in the summer of 2015 to calculate its reliability and repeatability for a 4-week interval during 2 phases of responding. Samples were selected using simple random sampling. All subjects entered the study with full satisfaction and questionnaires were filled anonymously using a code given by the secretary of the same NGO population to participants. Participants were asked to specify any ambiguities in any section of the questionnaire or the words used in it, and to write down their reason for ambiguity.

2.2.2.2. Calculating Intra-Class Correlation (ICC) and Cronbach's alpha:

To measure reliability in repeatability domain, intra-class correlation coefficient was used. The total intra-class correlation coefficient was calculated in pre-test and post-test stages by comparing the total score of the questionnaire. Cronbach's alpha was also used to assess reliability in the domain of internal consistency reliability. The acceptable ICC and Cronbach's alpha were considered higher than 0.7, obtaining a lower score for each question resulted in more assessment of that question and applying required changes while consulting related experts and specialists. Finally, SPSS21 was used to analyze data. 


\section{Results}

\subsection{Validity}

The response rate of experts and specialists in an interval of 2 to 3 weeks was about $93 \%(n=25)$. The relevance and clarity indices of the questions were calculated considering experts' views for the validity of the tool. Results showed that relevance of the questions was favorable (over 90\%) in all domains. The clarity of questions was favorable in the domains of participation, critical thinking, adaptability and social support; however, it was less satisfactory in the domains of self-efficacy (78.14), intention (81.08), motivation (79.48), and perceived control (78.85). To overcome the lack of clarity of the questions of these four domains, while consulting experts and specialists in this field, seven questions were removed due to low relevance. Nine questions were merged due to high similarity in content and were converted into four questions after correction. In addition, 14 questions were edited in terms of writing. At this stage, a questionnaire with 46 questions was obtained, including intention, participation, and adaptability domains (4 question each), motivation and perceived control (5 question each), selfefficacy (6 questions), social support (7 questions), and critical thinking (11 questions). The corrected questionnaire was again assessed and approved by experts. The total integrity of the tool was $94 \%$.

\subsection{Exploratory Factor Analysis}

After conducting exploratory factor analysis on the questionnaire with 46 questions, results of several main outputs were presented as follows: The first output provided the value of calculated KMO index, which was 0.896 in this study. Therefore, the selected sample size suffices to conduct factor analysis. In addition, Bartlett's Test of Sphericity showed the relevance of factor analysis at $p<0.001$ level to recognize the structure of factor model that indicated the discoverable relationships between variables, which were under factor analysis. The second output of exploratory factor analysis included values related to the initial factor and extracted factor. At this stage, nine items were removed due to achieving the factor load of less than 0.5 and 37 items or questions remained, for which the value of extracted factors was between 0.51 and 0.82 . The third output involved three parts of initial eigenvalues, eigenvalue of extracted factors without rotation, and eigenvalue of extracted factors with rotation. In this study, by extrapolating eigenvalues of more than one and the slope of scree plot, eight factors with predictive ability of $66.1 \%$ of the total changes in psychological empowerment were extracted and selected. The fourth output encompasses the rotated matrix of the components that includes factor load of each one of the variables in the remaining factors after rotation. This output includes eight factors with maximum and minimum fluctuating eigenvalues of 10.857 and 1.161 respectively. All questions of "intention", "social support", and "perceived control" domains were loaded in the same category as the original questionnaire. In the participation domain, questions 1,2, and 3 were loaded in the same category as the original questionnaire, and question 4 was loaded in the motivation domain. In the motivation domain, of four available questions, questions 6,7 , and 8 were loaded in the same domain and question 5 was loaded in the participation domain. In the critical thinking domain, of eight questions that remained in the original questionnaire, questions 13,15 , and 20 were loaded in the same category as the original questionnaire. Question 10 was loaded in the motivation domain and the remaining questions of 11,16, and 17 were loaded in a new domain called cognitive thinking considering the concept of questions and reviewing studies. In the adaptability domain of the two remaining questions, none of them were loaded in the domain similar to the original questionnaire such that question 21 was loaded in the critical thinking and question 24 in the self-efficacy domain and therefore, the adaptability domain was removed from the questionnaire. Of four questions available in the self-efficacy domain, questions 29,30 , and 31 were loaded in the same category as the original questionnaire. However, question 32 was loaded in the perceived control domain. Ultimately, eight domains with loaded questions resulted from the rotary approach to factor analysis were obtained as Table 1.

\subsection{Reliability}

Table 2 shows the reliability of eight domains' empowerment tool. All 36 female NGO members who filled the questionnaire in the first step, refilled the questionnaire after 4 weeks (100\%). Mean age and standard deviation of participants was 46.4 years and $\mathrm{SD}=9$, and duration of their membership in an $\mathrm{NGO}$ was 8.3 years and $\mathrm{SD}=6.1$. At this stage, according to the respondents, question 12 was edited because it was not understood.

\subsection{Results of the questionnaire}

The final empowerment questionnaire with Cronbach's alpha of 0.81 and ICC $=0.97$, including 37 items was obtained in eight domains (Table 2). 
Table 1. Factor Analysis with rotational approach among the eight given factors

\begin{tabular}{|c|c|c|c|c|c|c|c|c|c|}
\hline Factors & $\begin{array}{l}\text { Question } \\
\text { item no. }\end{array}$ & Participation & Motivation & $\begin{array}{l}\text { Cognitive } \\
\text { thinking }\end{array}$ & $\begin{array}{l}\text { Critical } \\
\text { thinking }\end{array}$ & Intention & $\begin{array}{l}\text { Self- } \\
\text { Efficacy }\end{array}$ & $\begin{array}{l}\text { Perceived } \\
\text { control }\end{array}$ & $\begin{array}{l}\text { Social } \\
\text { support }\end{array}$ \\
\hline \multirow{4}{*}{ Participation } & 1 & 0.783 & - & - & - & - & - & - & - \\
\hline & 2 & 0.791 & - & - & - & - & - & - & - \\
\hline & 3 & 0.708 & - & - & - & - & - & - & - \\
\hline & 5 & 0.635 & - & - & - & - & - & - & - \\
\hline \multirow[t]{5}{*}{ Motivation } & 4 & - & 0.832 & - & - & - & - & - & - \\
\hline & 6 & - & 0.516 & - & - & - & - & - & - \\
\hline & 7 & - & 0.718 & - & - & - & - & - & - \\
\hline & 8 & - & 0.681 & - & - & - & - & - & - \\
\hline & 10 & - & 0.414 & - & - & - & - & - & - \\
\hline \multirow{3}{*}{$\begin{array}{l}\text { Cognitive } \\
\text { thinking }\end{array}$} & 11 & - & - & 0.484 & - & - & - & - & - \\
\hline & 16 & - & - & 0.731 & - & - & - & - & - \\
\hline & 17 & - & - & 0.683 & - & - & - & - & - \\
\hline \multirow{4}{*}{$\begin{array}{l}\text { Critical } \\
\text { thinking }\end{array}$} & 13 & - & - & - & 0.670 & - & - & - & - \\
\hline & 15 & - & - & - & 0.636 & - & - & - & - \\
\hline & 20 & - & - & - & 0.507 & - & - & - & - \\
\hline & 21 & - & - & - & 0.587 & - & - & - & - \\
\hline \multirow[t]{5}{*}{ Intention } & 19 & - & - & - & - & 0.608 & - & - & - \\
\hline & 25 & - & - & - & - & 0.710 & - & - & - \\
\hline & 26 & - & - & - & - & 0.596 & - & - & - \\
\hline & 27 & - & - & - & - & 0.581 & - & - & - \\
\hline & 28 & - & - & - & - & 0.452 & - & - & - \\
\hline \multirow{4}{*}{$\begin{array}{l}\text { Self- } \\
\text { Efficacy }\end{array}$} & 24 & - & - & - & - & - & 0.426 & - & - \\
\hline & 29 & - & - & - & - & - & 0.811 & - & - \\
\hline & 30 & - & - & - & - & - & 0.851 & - & - \\
\hline & 31 & - & - & - & - & - & 0.737 & - & - \\
\hline \multirow{5}{*}{$\begin{array}{l}\text { Perceived } \\
\text { control }\end{array}$} & 32 & - & - & - & - & - & - & 0.620 & - \\
\hline & 36 & - & - & - & - & - & - & 0.625 & - \\
\hline & 37 & - & - & - & - & - & - & 0.687 & - \\
\hline & 38 & - & - & - & - & - & - & 0.488 & - \\
\hline & 39 & - & - & - & - & - & - & 0.618 & - \\
\hline \multirow{7}{*}{$\begin{array}{l}\text { Social } \\
\text { support }\end{array}$} & 40 & - & - & - & - & - & - & - & 0.821 \\
\hline & 41 & - & - & - & - & - & - & - & 0.832 \\
\hline & 42 & - & - & - & - & - & - & - & 0.830 \\
\hline & 43 & - & - & - & - & - & - & - & 0.805 \\
\hline & 44 & - & - & - & - & - & - & - & 0.776 \\
\hline & 45 & - & - & - & - & - & - & - & 0.694 \\
\hline & 46 & - & - & - & - & - & - & - & 0.803 \\
\hline
\end{tabular}

Table 2. Reliability of eight domains' empowerment tool

\begin{tabular}{|c|c|c|c|}
\hline Domains & Phrases or Questions & $\begin{array}{l}\text { Cronbach's } \\
\text { alpha }\end{array}$ & ICC \\
\hline \multirow[t]{4}{*}{ Participation } & Participating in social activities is one of my interests. & \multirow[t]{4}{*}{0.82} & \multirow[t]{4}{*}{0.90} \\
\hline & My participation in social activities is voluntary. & & \\
\hline & My participation in social activities is useful for my society and me. & & \\
\hline & I am motivated to participate in social affairs. & & \\
\hline \multirow[t]{5}{*}{ Motivation } & If people unite, they will be more capable of solving the problems of society. & \multirow[t]{5}{*}{0.79} & \multirow[t]{5}{*}{0.87} \\
\hline & When I try to focus on community issues, I feel worthiness within me. & & \\
\hline & By doing my tasks and duties better, I can make peace in my surrounding. & & \\
\hline & I can feel sympathetic to those around me, by paying heed to the community's issues. & & \\
\hline & $\begin{array}{l}\text { By investigating and analyzing my own and others' thinking, I can raise my awareness } \\
\text { of the problems and issues in society. }\end{array}$ & & \\
\hline \multirow{3}{*}{$\begin{array}{l}\text { Cognitive } \\
\text { thinking }\end{array}$} & I have the ability to distinguish between the facts in society and the guesses and rumors. & \multirow[t]{3}{*}{0.63} & \multirow[t]{3}{*}{0.78} \\
\hline & Asking about thigs I do not know helps my progress. & & \\
\hline & It is important to think about what to believe and what to do. & & \\
\hline \multirow{2}{*}{$\begin{array}{l}\text { Critical } \\
\text { thinking }\end{array}$} & Understanding existing problems in society helps me to interpret and root issues. & \multirow[t]{2}{*}{0.71} & \multirow[t]{2}{*}{0.82} \\
\hline & I have the ability to compare the issues of my society with issues of other communities. & & \\
\hline
\end{tabular}




\begin{tabular}{|c|c|c|c|}
\hline & Critical thinking skills prevent mental and social harm. & & \\
\hline & I have the ability to adapt to problems in society. & & \\
\hline \multirow[t]{5}{*}{ Intention } & I require thinking to predict the outcomes of my deeds and behavior. & \multirow[t]{5}{*}{0.81} & \multirow[t]{5}{*}{0.93} \\
\hline & My decision to engage in social activities is serious. & & \\
\hline & Participating in social activities is my upcoming program. & & \\
\hline & I have decided to take part in social activities with thought. & & \\
\hline & Participation in social activities is essential for my continued work. & & \\
\hline \multirow[t]{4}{*}{ Self-efficacy } & I have the ability to examine and try to solve the problems of my community. & \multirow[t]{4}{*}{0.86} & \multirow[t]{4}{*}{0.93} \\
\hline & I have the required knowledge to affect the social environment. & & \\
\hline & I have the required skills to affect the social environment. & & \\
\hline & I am sure that I have the ability to create required changes in the social environment. & & \\
\hline \multirow{5}{*}{$\begin{array}{l}\text { Perceived } \\
\text { control }\end{array}$} & I am confident in my ability to deal with the problems that come into my life. & \multirow[t]{5}{*}{0.81} & \multirow[t]{5}{*}{0.93} \\
\hline & $\begin{array}{l}\text { In case of any problem that occurs for my family, or myself I have the required } \\
\text { information to resolve the problems. }\end{array}$ & & \\
\hline & $\begin{array}{l}\text { In cases of problems that occur for my family or myself, I have the required abilities to } \\
\text { resolve them. }\end{array}$ & & \\
\hline & $\begin{array}{l}\text { In cases of problems that occur for my family or myself, there are resources and } \\
\text { facilities that I can use to solve them. }\end{array}$ & & \\
\hline & Having a cheerful spirit helps me to deal with life problems. & & \\
\hline \multirow[t]{7}{*}{ Social support } & I am confident that my family and relatives are absolutely honest with me. & \multirow[t]{7}{*}{0.92} & \multirow[t]{7}{*}{0.93} \\
\hline & I am confident that my family and relatives keep their promises. & & \\
\hline & I am confident that my family and relatives share important information with me. & & \\
\hline & I am confident that my comments are being used by my family and relatives. & & \\
\hline & I am confident that my family and relatives support me when I need them. & & \\
\hline & I am confident that my family and relatives are happy about my success and prosperity. & & \\
\hline & I am confident that my family and relatives put great value on what I do. & & \\
\hline
\end{tabular}

\section{Discussion}

Organized and volunteer communities play an important role in social participation and creating health-related social and cultural changes. The level of empowerment in these people has a direct effect on their individual and group function (19). Empowerment is considered as the first outcome of many health interventions, especially in women, and paying special attention to clinical and physical symptoms and changes resulted from interventional plans in the health domain, should not lead to neglecting this important aspect of attitudinal and behavioral changes. Empowerment refers to enabling women to earn resources and skills to better adapt to the current situation and be more prepared when facing future issues. The psychological empowerment tool in this study was designed with the aim of measuring empowerment in a group of NGO women (Health Companions). This tool includes 37 items on the domains of participation, motivation, critical thinking, cognitive thinking, intention, self-efficacy, perceived control as well as social support. The mentioned domains were obtained via reviewing texts and surveying experts and they comply with empowerment domains in other studies $(12,21-23)$. The mean value obtained for relevance of this tool was between 90 and $100 \%$, which shows the good relevance of this tool $(24,25)$. High value of relevance shows that among abundant available questions for each domain, the selected questions have been proper options (26). These results show the high agreement of experts on relevance and clarity. In this study, the general comprehensiveness of the tool was $94 \%$. Therefore, it could be considered as a comprehensive and complete tool. In sum, with regard to the high relevance, clarity and comprehensiveness of the corrected tool, it could be introduced as a proper tool for the specified target community. The value of ICC in the studies where the tool to measure empowerment was designed for various groups in the health system, has been reported between 0.71 and 0.96 (27). Results of this section comply with other studies that investigated the validity of various empowerment questionnaires, including the study by Hansson, Cheryomukhin, Man, and Koren (28, 29-31). For instance, the value of ICC in the study by Cheryomukhin et al., where the validity of empowerment questionnaire in Azerbaijan was investigated, was 0.8 . The values obtained in exploratory factor analysis for structural validity of this tool, verify the factor analysis model and indicate its relevance for the data of this study (32). Not loading all questions in the initial domain of the questionnaire that occurred in this study could be justified considering results of other psychometric studies, where loading of items has not been entirely consistent with the original questionnaire (33). Results of the study by Haswell (2010) during the psychometric process of psychological empowerment in an Australian society show that in just one domain of the three domains of the questionnaire, loading questions has occurred in the same original field. In this study, the highest changes in loading were related to the domain of critical thinking, such that three questions of "I have the ability to distinguish between the facts in society and the guesses and rumors", 
"Asking about things I do not know helps my progress", and "It is important to think about what to believe and what to do" that were in the original questionnaire in the domain of critical thinking, were separated from it after loading and were loaded in a new domain called cognitive thinking considering the concept of questions. Perhaps one of the reasons for this is the semantic proximity of these two domains, such that cognitive thinking can be considered as the basis of critical thinking (35). The study by Veugelers (2007) shows that a high level of knowledge and having the power of thinking has increased critical thinking in the studied population and has played a significant role in correct citizenship behavior (36). In the domain of self-efficacy, question 32, i.e. "I am confident in my ability to deal with the problems that occur in life," was loaded into the domain of perceived control. Schulz (1995) has introduced perceived control as one of the components that is quite relevant to a variety of psychological, group, and organizational capabilities (37). In the psychometric process of empowerment tool, results of the study by Menon (1999) have shown perceived control, perceived capability and internal objective with reliability coefficient of 0.83 , 0.80 , and 0.88 respectively (21). Among studies conducted on psychological empowerment, the study by Maunsell (2014) could be mentioned, who designed the empowerment questionnaire to determine empowerment of patients with cancer. In this study, first, 739 patients filled the intended questionnaire encompassing 25 questions on five dimensions of social support, the course of health services, adaptive attitudes and approach, learning skills and techniques, and emotional concern. Then, validity and reliability of the questionnaire was measured using quantitative and qualitative methods. Cronbach's alpha of various items of the questionnaire were reported between 0.75 and 0.90 . The 5 -factor model was also approved via confirmatory factor analysis (38). Results of the process of measuring the reliability of the questionnaire showed that the Cronbach's alpha of the final version of this questionnaire was 0.81 and the correlation coefficients of dimensions of the questionnaire were 0.78 to 0.93 in retest. Most available versions of empowerment questionnaire demonstrated a reliability of over 0.7 (39-41). Results of the study by Morrison (2014) shows that Cronbach's alpha of the youth empowerment questionnaire was between 0.87 and 0.90 (42).

\section{Conclusions}

Findings of the study showed that the questionnaire of this study is in a satisfactory state and can be used for the target community. The declared values of validity and reliability of this questionnaire have also made it a valid questionnaire. Functional importance of these findings is that a questionnaire was obtained to determine individuals' psychological empowerment that was not directly investigated earlier. In addition to realizing the objectives of this study, this questionnaire is proportional to the culture and conditions of the target group in Iran. It is suggested to employ this questionnaire for other groups and communities to increase its generalizability and to determine its reliability and compare it with results of the present study again. Conducting a supplementary research on determining the areas of psychological empowerment with a similar methodology can be a good way to ensure the coverage of all the dimensions required in the questionnaire.

\section{Acknowledgments:}

This study is part of the $\mathrm{PhD}$ dissertation in Health Education and Health Promotion to the grant number of 9123489002. Authors of this study greatly appreciate the reverend Research Deputy of International Campus of Tehran University of Medical Sciences for approval and financial support of this project, as well as all Mental Health Companions of Guilan Province known as a group who were active volunteers at NGOs and sincerely participated in various stages of this study. In addition, the Welfare Organization of Guilan Province is appreciated for cooperating in the implementation of this study.

\section{Conflict of Interest:}

There is no conflict of interest to be declared.

Authors' contributions:

All authors contributed to this project and article equally. All authors read and approved the final manuscript.

\section{References:}

1) Balouei E, Bagherzadeh M, Tabari M, Roshanbakhsh F. The empowerment of NGOs in Mazandaran province. Journal of Management efficiency.2011;5(18):99-123.

2) Nikkhah HA, Redzuan Mr. The role of NGOs in promoting empowerment for sustainable community development. Journal of Human Ecology. 2010;30(2):85-92.

3) Adegoroye AA, Adegoroye AA. The roles of selected NGOs in economic empowerment of rural women in Ibadanland, Nigeria. Gender \& Behaviour. 2008;6(2):1870. doi: 10.4314/gab.v6i2.23425 
4) Yasouri $\mathrm{m}$. The role of NGOs in rural youths and women Empowerment (Case of Ardogash Village). Journal of Human settlements planning studies. 2012;6(17):44-60.

5) Behzisty organization of Guilan. Iran: Organization of welfare online Resources; 2015-01 [updated 2016 July 25]. Available from: http://www.behzisty-guilan.ir/.

6) Heritage Z, Dooris M. Community participation and empowerment in Healthy Cities. Health Promotion International. 2009;24(suppl 1):i45-i55. doi: 10.1093/heapro/dap054, PMid: 19914988

7) Tangney JP, Baumeister RF, Boone AL. High self-control predicts good adjustment, less pathology, better grades, and interpersonal success. Journal of personality. 2004;72(2):271-324. doi: 10.1111/j.00223506.2004.00263.x, PMid: 15016066

8) Israel BA, Checkoway B, Schulz A, Zimmerman M. Health education and community empowerment: conceptualizing and measuring perceptions of individual, organizational, and community control. Health Education \& Behavior. 1994;21(2):149-70. doi: 10.1177/109019819402100203

9) Oman RF, Vesely SK, Mcleroy KR, Harris-Wyatt V, Aspy CB, Rodine S, et al. Reliability and validity of the Youth Asset Survey (YAS). Journal of Adolescent Health. 2002;31(3):247-55. doi: 10.1016/S1054139X(02)00363-4

10) Reininger B, Evans A, Griffin S, Valois R, Vincent M, Parra - Medina D, et al. Development of a youth survey to measure risk behaviors, attitudes and assets: Examining multiple influences. Health education research. 2003;18(4):461-76. doi: 10.1093/her/cyf046, PMid: 12939128

11) Spreitzer GM. Psychological empowerment in the workplace: Dimensions, measurement, and validation. Academy of management Journal. 1995;38(5):1442-65. doi: 10.2307/256865

12) Handy F, Kassam M, Contact P, editors. Women's empowerment in rural India. International Society for Third Sector Research Conference, Toronto Canada; 2004. PMCid: PMC368438

13) Shirazi M, Manoochehri M, Zagheri Tafreshi M, Zayeri F. Development and psychometric evaluation of chronic pain acceptance instrument in the elderly. Journal of Anesthesiology and Pain. 2015;5(2):33-47.

14) Abdollahpour I, Nedjat S, Majdzadeh R. Performing content validation process in development of questionnaires. Iranian Journal of Epidemiology. 2011;6(4):66-74.

15) Zagheri Tafreshi M, Yaghmaie F. Application of factor analysis in structural validity measurement. J Teb va Tazkiyeh. 2005;14(3):50-60.

16) Knapp TR, Brown JK. Ten measurement commandments that often should be broken. Research in Nursing \& Health. 1995;18(5):465-9. doi: 10.1002/nur.4770180511

17) Bland JM, Altman DG. Statistics notes: Cronbach's alpha. Bmj. 1997;314(7080):572. doi: 10.1136/bmj.314.7080.572

18) Altman L, Kuhlmann AKS, Galavotti C. Understanding the black box: A systematic review of the measurement of the community mobilization process in evaluations of interventions targeting sexual, reproductive, and maternal health. Evaluation and program planning. 2015;49:86-97. doi: 10.1016/j.evalprogplan.2014.11.010, PMid: 25615599

19) Johnson DM, Worell J, Chandler RK. Assessing psychological health and empowerment in women: The personal progress scale revised. Women \& health. 2005;41(1):109-29. doi: 10.1300/J013v41n01_07, PMid: 16048871

20) Kasmel A, Tanggaard P. Evaluation of changes in individual community-related empowerment in community health promotion interventions in Estonia. International journal of environmental research and public health. 2011;8(6):1772-91. doi: 10.3390/ijerph8061772, PMid: 21776201, PMCid: PMC3137996

21) Menon ST. Psychological empowerment: Definition, measurement, and validation. Canadian Journal of Behavioural Science/Revue canadienne des sciences du comportement. 1999;31(3):161. doi: 10.1037/h0087084

22) Neilsen AR. Critical Thinking and Reading: Empowering Learners To Think and Act. Monograph on Teaching Critical Thinking Number 2: ERIC; 1989.

23) Wathieu L, Brenner L, Carmon Z, Chattopadhyay A, Wertenbroch K, Drolet A, et al. Consumer control and empowerment: A primer. Marketing Letters. 2002;13(3):297-305. doi: 10.1023/A:1020311914022

24) Grant JS, Davis LL. Selection and use of content experts for instrument development. Research in nursing \& health. 1997;20:269-374. doi: 10.1002/(SICI)1098-240X(199706)20:3<269::AID-NUR9>3.0.CO;2-G

25) Tengland P-A. Empowerment: A conceptual discussion. Health Care Analysis. 2008;16(2):77-96. doi: 10.1007/s10728-007-0067-3, PMid: 17985247

26) Beckstead JW. Content validity is naught. International journal of nursing studies. 2009;46(9):1274-83. doi: 10.1016/j.ijnurstu.2009.04.014, PMid: 19486976 
27) Herbert RJBNMNP, Gagnon AJRNMPHP, Rennick JERNMP, O'Loughlin JLP. A Systematic Review of Questionnaires Measuring Health-Related Empowerment. Research and Theory for Nursing Practice. 2009;23(2):107-32. doi: 10.1891/1541-6577.23.2.107

28) Hansson L, Björkman T. Empowerment in people with a mental illness: reliability and validity of the Swedish version of an empowerment scale. Scandinavian Journal of Caring Sciences. 2005;19(1):32-8. doi: 10.1111/j.1471-6712.2004.00310.x, PMid: 15737163

29) Cheryomukhin AM. Development and validation of the Azerbaijani empowerment scale: Support and new implications for theory [Ph.D.]. Ann Arbor: Rutgers The State University of New Jersey - New Brunswick; 2014. PMid: 24737007

30) Man D. A preliminary study to investigate the empowerment factors of survivors who have experienced brain damage in rehabilitation. Brain injury. 2001;15(11):961-73. doi: 10.1080/02699050110065664, PMid: 11689094

31) Koren PE, DeChillo N, Friesen BJ. Measuring empowerment in families whose children have emotional disabilities: A brief questionnaire. Rehabilitation Psychology. 1992;37(4):305. doi: 10.1037/h0079106

32) Goldberg LR, Digman JM. Revealing structure in the data: Principles of exploratory factor analysis. 33.Differentiating normal and abnormal personality. 1994:216-42.

33) Mahmoodi Shan Gh, Rahmani H, Rouhi Gh, Vakili MA, Hosseini SA. Psychometry of professional nurses self concept. Journal of Nursing and Midwifery Urmia University of Medical Sciences. 2015:14(3):302-10.

34) Haswell MR, Kavanagh D, Tsey K, Reilly L, Cadet-James Y, Laliberte A, et al. Psychometric validation of the Growth and Empowerment Measure (GEM) applied with Indigenous Australians. Australian and New Zealand Journal of Psychiatry. 2010;44(9):791-9. doi: 10.3109/00048674.2010.482919, PMid: 20815665

35) Fairclough N. Critical language awareness. 3ed. New York: Routledge; 2014.

36) Veugelers W. Creating critical - democratic citizenship education: empowering humanity and democracy in Dutch education. Compare: A Journal of Comparative and International Education. 2007;37(1):105-19. doi: 10.1080/03057920601061893

37) Schulz AJ, Israel BA, Zimmerman MA, Checkoway BN. Empowerment as a multi-level construct: perceived control at the individual, organizational and community levels. Health Education Research. 1995;10(3):309-27. doi: 10.1093/her/10.3.309

38) Maunsell E, Lauzier S, Brunet J, Pelletier S, Osborne RH, Campbell HS. Health - related empowerment in cancer: Validity of scales from the Health Education Impact Questionnaire. Cancer. 2014;120(20):3228-36. doi: 10.1002/cncr.28847, PMid: 24988944

39) Spreitzer GM. Taking stock: A review of more than twenty years of research on empowerment at work. Handbook of organizational behavior. 2008:54-72.

40) Homko CJ, Sivan E, Reece EA. The Impact of Self-Monitoring of Blood Olucose on Self-Efficacy and Pregnancy Outcomes in Women With Diet-Controlled Gestational Diabetes. The diabetes educator. 2002;28(3):435-43. doi: 10.1177/014572170202800313, PMid: 12073958

41) Shiu AT, Martin CR, Thompson DR, Wong RY. Psychometric properties of the Chinese version of the diabetes empowerment scale. Psychology, health \& medicine. 2006;11(2):198-208. doi: 10.1080/13548500500286845, PMid: 17129908

42) Morrison PM. Exploring the Role of Psychological Self-Empowerment and Self Esteem in the Development of Adolescent Leadership Self-Efficacy: A Mediational Analysis [Ph.D.]. Ann Arbor: Alliant International University; 2014. 